\title{
CONVERGENCE OR DIVERGENCE: A FUZZY CLUSTERING ANALYSIS OF SOUTHEAST ASIAN ECONOMIC SYNCHRONIZATION
}

\author{
Toan Ngoc NGUYEN \\ Lecturer, Institute of Economics, Ho Chi Minh Academy of Politics, Vietnam. \\ DOI: 10.46609/IJSSER.2020.v05i03.008 URL: https://doi.org/10.46609/IJSSER.2020.v05i03.008
}

\begin{abstract}
This paper attempts to examine the degree of homogeneity and the trend of macroeconomic convergence across East Asian economies from the perspective of multiple Optimum Currency Area criteria, using the technique of fuzzy C-mean clustering analysis. The question of homogeneity is obviously of importance to the test the convergence in East Asia and to formulate any regional policy coordination. We find that East Asia has not been sufficiently homogeneous and can be divided into as many as four to five groups with significant degree of fuzziness. We find no notable trend of convergence from the data. In fact, East Asian has appeared to be more diverged. Thus, we suspect the possibility of common policy stance and of forming a currency union in East Asia.
\end{abstract}

Keywords: East Asia, Fuzzy Clustering Analysis, Macroeconomic Convergence, Optimum Currency Area

\section{INTRODUCTION}

There has been a paucity of empirical studies on the synchronization and convergence of East Asian economies despite growing integration in the region. As intra-regional trade has increased in the past decades, one might expect that the East Asian economies become increasingly converged. However, East Asian economies are very different in the level of development and that they may exhibit very different business cycles and other indicators. Some studies have examined the homogeneity across East Asian economies. For example, Chow and Kim [1] investigate the symmetry of shocks using a structural VAR framework and find that East Asia economies are structurally different from each other and thus likely to be subject to asymmetric shocks. These studies, however, analyzes each type of shock separately and do not consider 
International Journal of Social Science and Economic Research

ISSN: $2455-8834$

Volume: 05, Issue: 03 "March 2020"

other criteria in the Optimum Currency Area (OCA) theory. The OCA lay out several criteria measuring the macroeconomic convergence of economies. While shock symmetry is important, other criteria come into play as well.

This paper attempts to examine the degree of homogeneity and macroeconomic convergence in East Asia from the perspective of multiple OCA criteria, using the technique of fuzzy C-mean clustering analysis. East Asia in our paper refers to ten economies in the region: Japan, Korea (Republic), China (Mainland), Hong Kong (district of China), Taiwan (province of China), Singapore, Malaysia, Thailand, Indonesia and the Philippines. The question of homogeneity and macroeconomic convergence is obviously of importance to understand the economic integration in the region and to foster any regional policy coordination. If the economies are homogeneous, similar policies and coordinated policies can be implemented.

Heterogeneous economies would, however, face with dissimilar benefit - cost tradeoffs and thus prefer heterogeneous policies. The aim of fuzzy clustering analysis is to assign each East Asian economies, with various degree of fuzziness, to a group to which it is most similar in terms of a chosen set of OCA criteria. The advantage of the method is that it can take into consideration not one but multiple criteria at the same time and thus, produce a more comprehensive picture of the degree of homogeneity across East Asian economies. To capture the evolution of convergence, we employ a dataset of 2 periods: $1990-2000$ and 2001-2018, given our accessible data sources.

To anticipate our results, we find that East Asia economies have not been much homogeneous and can be classified into about four groups with significant degree of fuzziness. The regional financial crisis has negative influence on the convergence of economies in the region. Our results indicate a divergence of East Asia in the aftermath of the crisis. Thus, we are unconvinced about the formation of a currency union in the area in the near future.

The rest of the paper is deployed as follow. Section 2 briefly describes the technique of fuzzy Cmean clustering analysis employed in our paper. In Section 3, we apply the technique to a set of selected OCA criteria to partition East Asian economies into different groups. The final section is as usual, conclusion.

\section{MATERIALS AND METHODS}

\section{OCA Criteria and the Grouping of East Asian Economies}

Traditional analyses of the OCA theory are typically conceived in terms of balancing the micro benefits gained by expanding the currency domain against the macroeconomic costs of giving up 


\section{International Journal of Social Science and Economic Research}

ISSN: $2455-8834$

Volume: 05, Issue: 03 "March 2020"

monetary autonomy and a separate exchange rate, which are important tools of macroeconomic adjustments. Monetary autonomy is not necessarily good, however, since it might be a destabilizing source once used improperly. The OCA theory outlines conditions or criteria with which a economy can reap large benefit and/or substantially reduce the cost of joining a currency union. Talvas [2] listed nine criteria from traditional literature: the similarity of inflation rates, the degree of factor mobility, the openness and size of the economy, the degree of industrial diversification, price and wage flexibility, the degree of goods market integration, fiscal integration, real exchange rate variability and political factors. Other criteria not listed in this survey but can be easily found in many other surveys of OCA literature, such as Masson and Taylor [3], [4]. These are the synchronization of business cycles, the degree of currency substitution and the credibility of monetary policy. In this paper, we apply fuzzy clustering analysis to East Asian economies with a set of selected variables inspired by the OCA criteria. The economies are treated as objects in fuzzy clustering analysis. The purpose is to uncover the similarities across East Asian economies in respect of those variables so as to assign the economies into groups which are internally homogeneous. We select five important variables of which the data are within our reach: 1) the synchronization of business cycles; 2) the volatility of real exchange rates against US dollar; 3) the degree of openness to regional trade; 4) inflation differentials against the regional average and 5) the degree of export diversification. These variables are briefly defined below:

Synchronization of business cycles: one of the most important OCA criteria is the synchronization of business cycles. If business cycles are highly synchronized, the cost of foregoing independent monetary policy is reduced since a common monetary policy can serve all economies well. A simple measure of the degree of synchronization is the simple crosscorrelation coefficient between the cyclical components of each economy with that of the centered economy chosen to represent the region. Bayoumi and Eichengreen [5] suggest a similar but more complicated measure: the cross-correlation coefficients of output shocks identified through a structural VAR framework à la Blanchard and Quad [6].

Pivotal in these approaches are the choice of the centered economy. For EU or Northern America, finding a centered economy is fairly easy since Germany and the United States are respectively the natural leaders in their regions. Yet, it is not the case in East Asia. Japan is the biggest economy in this area but its business cycle is significantly different from those of the rest of the region [1]. No other economies are qualified as the regional center. To get around this issue, we employ the tool of factor analysis to construct the regional business cycle as the (unobserved) common cycle shared across East Asia. We assume that the business cycle in each economy consists of two parts: a common part called the common factor, which is also the 


\section{International Journal of Social Science and Economic Research}

ISSN: $2455-8834$

Volume: 05, Issue: 03 "March 2020"

regional business cycle; and an idiosyncratic part that is unique in the economy. The factor model is as follows:

$$
y i=\alpha_{i} F+\varepsilon_{i}
$$

where $y_{i}$ is the cyclical component of economy i output, $\alpha_{i}$ is the correlation coefficient measuring the degree of synchronization, $\mathrm{F}$ is the unobserved common factor and $\varepsilon_{i}$ is the idiosyncratic part of the business cycle in economy $\mathrm{i}$. The model is estimated using maximum likelihood. More complicated versions of factor analysis has been used in, among others, Gregory et al [7] and Kose et al [8] to derive international business cycle. Annual GDP data are used as the proxy of aggregate outputs. To segregate the cyclical components from GDP, we take log and first difference the series. Since estimation results might be sensitive to the choice of detrending methods, we also attempt another wellknown detrending technique, the Hodrik - Prescott [9] filter with dampening parameter of 100 .

Volatility of real exchange rates: the cost of a currency union is associated with the abandonment of an independent monetary policy and a separate exchange rate as a shock absorber. In the presence of adverse shocks, a central banker can adjust its monetary policy so as to affect the nominal exchange rate, expecting this would change the real exchange rate. If there has been little cause for real exchange rate volatility, the cost of abandoning a separate exchange rate would be presumably small. We measure real exchange rate variations as standard deviations of the log-difference of the quarterly real bilateral exchange rates vis à vis US dollar.

Openness to Trade: openness to regional trade involves both the benefit and the cost of joining a currency union. A more open economy is likely to reap greater benefits from the expansion of currency domain thank to reduced transaction costs and risks. On the other hand, the value of a separate exchange rate is relatively lower in the economy due to high ratio of traded goods to non-traded goods. A change in nominal exchange rate is likely to be followed by a change in domestic price and wage rather than a change in real exchange rate, reducing the effectiveness of exchange rate as a tool of trade balance adjustment. Thus, the more open a economy, the less the usefulness of domestic currency and the value of a separate exchange rate and the greater the benefit of a currency union. In this paper, we measure openness to trade as the ratio of trade with East Asian economies to total trade:

$$
\text { Openness }=\left(\mathrm{x}_{\mathrm{i}, \mathrm{EA}}+\mathrm{m}_{\mathrm{i}, \mathrm{EA}}\right) /\left(\mathrm{x}_{\mathrm{i}}+\mathrm{m}_{\mathrm{i}}\right)
$$

where $x_{i}$ and $m_{i}$ are annual total export and total import of economy $i, x_{i, E A}$ and $m_{i, E A}$ are economy i's annual export to and import from other East Asian economies. 


\section{International Journal of Social Science and Economic Research}

ISSN: $2455-8834$

Volume: 05, Issue: 03 "March 2020"

Inflation differentials: while traditional OCA criteria involve only real variables, recent developments have put a nominal variable to the list of criteria: inflation differentials across economies. When inflation rates are similar over time, the terms of trade will be fairly stable, underplaying the need for a separate exchange rate. Also, since similar inflation rates result from similarities in monetary and fiscal stance and economic structures, the cost of joining a currency union is presumably low. In this paper, inflation rates are computed from annual consumer price indices except for China, where inflation rate is reported directly.

Diversification of export: one of the original OCA criteria is the diversification of economic structure suggested by Kenen [10]. In a diversified economy, each of its sectors might be subject to shocks but if shocks are independent and the economy produces a sufficiently large variety of different goods, the law of large numbers will come into play and total production will not suffer much from shocks. Moreover, the changes in real exchange rate needed for adjustment to a single shock will be less in a diversified economy. Since we do not have data on economic structures in East Asia, export diversification is used as a proxy. To measure the degree of export diversification, we resort to the inverse of the period average of the annual Herfindahl indices, a popular indicator of the degree of specialization. Herfindahl index is computed as

$$
H=\sum_{i=1}^{n} s_{i}^{2}
$$

where $s_{i}$ is share of the export of product $\mathrm{i}, n$ is the number of products exported. As we do not have data on the export of individual products, we use annual export data broken down into ten first-digit sub-industries of the United Nation's Standard International Trade Classification (SITC), revision 2: $\underline{0}$ - Food and live animals; 1 - Beverages and tobacco; $\underline{2}$ - Crude materials, inedible, except fuels; $\underline{3}$ - Mineral fuels, lubricants and related materials; $\underline{4}$ - Animal and vegetable oils, fats and waxes; $\underline{5}$ - Chemicals and related products, n.e.s.; $\underline{6}$ - Manufactured goods classified chiefly by material; $\underline{7}$ - Machinery and transport equipment; $\underline{8}$ - Miscellaneous manufactured articles; $\underline{9}$ - Commodities and transactions not classified elsewhere in the SITC.

Data are obtained from various sources, notably Word Development Indicator (online), IMF Financial Data Statistics (online), IMF Direction of Trade Statistics (online), Taiwan Statistics Yearbook (online).

\section{Fuzzy C-mean Clustering Analysis}

Given that we have many variables, regression techniques appear inappropriate. We, therefore, employ clustering analysis to partition economies into groups. Clustering analysis is a wellknown technique for finding groups in data. The method is employed to uncover the similarities across different objects and to identify homogeneous subgroups in a given dataset. While hard 
International Journal of Social Science and Economic Research

ISSN: $2455-8834$

Volume: 05, Issue: 03 "March 2020"

clustering analysis attempts to assign each object to one and only one cluster (group), fuzzy clustering analysis allows some ambiguity in the data by assigning each object to a cluster with a probability indicating the degree of belongingness of the object to that cluster. The probabilities are termed membership coefficients. An object is most likely to belong to the cluster with which it has the highest membership coefficient. In this paper, we apply the fuzzy C-mean (FCM) algorithm, the most popular fuzzy clustering technique which was first introduced by Dunn (1973) and generalized to final form by Bezdek [11]. The algorithm can be described briefly as follows. Assuming that our dataset contains $n$ objects with $p$ variables for each object. The objects are denoted $X_{n p}=\left\{x_{1}, x_{2}, \ldots, x_{n}\right\}$, where $x_{i}$ is the vector of variables for object $i, x_{i}=\{$ $\left.\mathrm{x}_{\mathrm{i} 1}, \mathrm{x}_{\mathrm{i} 2}, \ldots, \mathrm{x}_{\mathrm{ip}}\right\}$. Suppose that we want to classify these objects into $c$ clusters. Each cluster is represented by its center $\mathrm{k}_{\mathrm{j}}(\mathrm{j}=1,2, . ., c)$. The aim of the fuzzy $\mathrm{C}$-mean algorithm is to minimize the objective function $\mathrm{J}$

$$
J=\sum_{i=1}^{n} \sum_{k=1}^{c} u_{i, j}^{m} d_{i, j}^{2}
$$

subject to the probabilistic condition: $u_{i j} \in[0,1]$ and $\sum_{j=1}^{c} u_{i, j}=1$, where $u_{i, j}$ is the membership coefficient of object $i$ to cluster $j, \mathrm{~m}$ is a fuzzifier parameter $(\mathrm{m}>1)$ and $\mathrm{d}_{\mathrm{i}, \mathrm{j}}$ is the dissimilarity (the distance) between object $i$ and the center $k_{j}$ of cluster $j$, measured by the Euclidian distance between them.

$$
d_{i, j}=\sqrt{\sum_{l=1}^{p}\left(x_{i, l}-k_{j, l}\right)^{2}}
$$

The center of cluster $j$ associating with the minimized objective function $J$ is identified by:

$$
k_{j}=\frac{\sum_{i=1}^{n} u_{i, j}^{m} x_{j}}{\sum_{i=1}^{n} u_{i, j}^{m}}
$$

The algorithm results in the matrix of membership coefficients $U$, whereby we can assign each object to a cluster to which it has highest membership. Details of the fuzzy C-mean algorithm and other clustering techniques are provided in, for example, Rayward-Smith et al [12].

The above algorithm is, however, based on the assumption that the number of cluster is already known. In reality, we have to choose the number of clusters so as to ensure that the clusters are as "crisp" as possible. To determine the optimal number of clusters, we rely on two popular validity tests which to us are most suitable for fuzzy clustering. The first test is the Xie and Beni [13] index: 


$$
X B=\frac{1}{n} \frac{\sum_{i=1}^{n} \sum_{j=1}^{c} u_{i, j}^{2} d_{i, j}^{2}}{\min \left\{\left(k_{j}-k_{v}\right) \mid j, v=1,2, . . c ; j \neq v\right\}}
$$

where, $k_{j}, k_{v}$ are the centers of cluster $j$ and cluster $v$ respectively. Smaller XB index indicates more compact and separated clusters.

Another useful statistics for validating a cluster partitioning is the silhouette width.

The silhouette width of an individual object $i$ is defined as:

$$
s(i)=\frac{b_{i}-a_{i}}{\max \left(a_{i}, b_{i}\right)}
$$

where $a_{i}$ is the average dissimilarity (distance) between object $i$ and all other objects in the same cluster and $b_{i}=\min \left\{b_{i j}, \mid j=1,2, \ldots, ; c j \neq i\right\} ; b_{\mathrm{ij}}$ is the average distance from object $i$ to all objects in cluster $j$. The value of silhouette width ranges from -1 to 1 . A value close to 1 indicates that the object is well-clustered while a value near zero signals high degree of fuzziness and the object might be better classified to a neighboring cluster. A negative silhouette value indicates that the object is misspecified. The average silhouette of all objects is an indicator showing how well the entire dataset is partitioned. An optimal number of clusters must be associated with positive individual silhouettes and large average silhouette.

\section{RESULTS AND DISCUSSION}

We perform the fuzzy clustering exercises on 2 periods: 1990-2000 and 2001-2018. The OCA criteria for the periods are presented in Table 1 and Table 2.

Table 1: OCA Variables in East Asian Economies (1990 - 2000)

\begin{tabular}{|l|c|c|c|c|c|}
\hline \multicolumn{1}{|c|}{ Economy } & $\begin{array}{c}\text { Business cycles } \\
\text { synchronization }\end{array}$ & $\begin{array}{c}\text { Exchange } \\
\text { rate volatility }\end{array}$ & $\begin{array}{c}\text { Trade } \\
\text { openness }\end{array}$ & $\begin{array}{c}\text { Inflation } \\
\text { differentials }\end{array}$ & $\begin{array}{c}\text { Export } \\
\text { diversification }\end{array}$ \\
\hline China & 0.219 & 0.033 & 0.527 & 1.637 & 3.399 \\
\hline Hong Kong & 0.804 & 0.020 & 0.665 & 0.477 & 3.106 \\
\hline Indonesia & 0.980 & 0.140 & 0.537 & 8.127 & 5.538 \\
\hline Japan & 0.612 & 0.058 & 0.357 & -4.398 & 1.935 \\
\hline Korea & 0.908 & 0.064 & 0.409 & -0.015 & 3.221 \\
\hline Malaysia & 0.989 & 0.040 & 0.565 & -1.966 & 3.325 \\
\hline Philippines & 0.428 & 0.050 & 0.459 & 3.156 & 3.363 \\
\hline
\end{tabular}


International Journal of Social Science and Economic Research

ISSN: 2455-8834

Volume: 05, Issue: 03 "March 2020"

\begin{tabular}{|l|l|l|l|l|l|}
\hline Singapore & 0.875 & 0.014 & 0.521 & -3.548 & 2.476 \\
\hline Taiwan & 0.676 & 0.057 & 0.474 & -2.707 & 3.101 \\
\hline Thailand & 0.951 & 0.062 & 0.494 & -0.764 & 4.217 \\
\hline
\end{tabular}

Table 2: OCA Variables in East Asian Economies (2001 - 2018)

\begin{tabular}{|l|c|c|c|c|c|}
\hline \multicolumn{1}{|c|}{ Economy } & $\begin{array}{c}\text { Business cycles } \\
\text { synchronization }\end{array}$ & $\begin{array}{c}\text { Exchange } \\
\text { rate volatility }\end{array}$ & $\begin{array}{c}\text { Trade } \\
\text { openness }\end{array}$ & $\begin{array}{c}\text { Inflation } \\
\text { differentials }\end{array}$ & $\begin{array}{c}\text { Export } \\
\text { diversification }\end{array}$ \\
\hline China & 0.416 & 0.020 & 0.343 & -0.250 & 12.805 \\
\hline Hong Kong & 0.857 & 0.022 & 0.622 & -0.683 & 15.448 \\
\hline Indonesia & 0.627 & 0.034 & 0.536 & 4.507 & 13.984 \\
\hline Japan & 0.558 & 0.037 & 0.423 & -2.325 & 11.592 \\
\hline Korea & 0.185 & 0.044 & 0.455 & 0.087 & 9.335 \\
\hline Malaysia & 0.870 & 0.015 & 0.539 & -0.174 & 12.118 \\
\hline Philippines & 1.000 & 0.021 & 0.571 & 1.451 & 9.624 \\
\hline Singapore & -0.024 & 0.012 & 0.575 & -0.815 & 16.536 \\
\hline Taiwan & 0.143 & 0.015 & 0.580 & -1.461 & 13.048 \\
\hline Thailand & 0.419 & 0.019 & 0.451 & -0.337 & 15.986 \\
\hline
\end{tabular}

Before analyzing the results of clustering partition, we first identify the optimal number of clusters based on the validity tests of Xie-Beni index and silhouette statistics. For each period, we run the validity test with increasing number of clusters, from two clusters to six clusters. Since we have only ten economies, it seems fair to limit the maximum number of clusters to six. The results of the validity tests are reported in Table 3. A well-clustered scheme is the one which has positive and large average silhouette and small Xie-Beni index.

For the period of 1990 - 2000, both the Xie - Beni index and the silhouette statistics suggest the optimal number of four groups. The average silhouette is highest at six groups but there we witness the existence of negative individual silhouettes. The highest average silhouette with positive individual silhouettes is found at four clusters. For the period of $2001-2018$, the XieBeni index is smallest with five clusters while the silhouette statistics is largest with 3 clusters. However, as the silhouette statistics is just slightly smaller with 5 clusters, we select 5 clusters for clustering analysis, since it best satisfies both tests. Once the number of clusters is selected, we perform fuzzy C-mean clustering analysis using the "fclust" and "ppclust" packages in R. The membership coefficients of fuzzy clustering analysis for the period of $1990-2000$ are presented in Table 4. For the purpose of this paper, we set the fuzziness parameter $\mathrm{m}=2$ as 
International Journal of Social Science and Economic Research

ISSN: $2455-8834$

Volume: 05, Issue: 03 "March 2020"

usual. we find significant degree of fuzziness as indicated by small silhouette width in many economies. Fuzzy clustering analysis with four groups is reported in Table 4.

Table 3: Validity Tests of Optimal Cluster Number

\begin{tabular}{|c|c|c|c|c|c|c|}
\hline \multicolumn{2}{|c|}{ Number of clusters } & 2 & 3 & 4 & 5 & 6 \\
\hline \multirow{2}{*}{$1990-2000$} & Xie - Beni & 1.207 & 1.288 & $\mathbf{1 . 1 6 1}$ & 1.205 & 1.250 \\
\cline { 2 - 7 } & $\begin{array}{c}\text { Average } \\
\text { Silhouette }\end{array}$ & 0.346 & 0.399 & $\mathbf{0 . 5 0 4}$ & 0.413 & 0.513 \\
\hline $2001-2018$ & Xie - Beni & 0.775 & 0.237 & 0.141 & $\mathbf{0 . 1 3 1}$ & 0.775 \\
\cline { 2 - 7 } & $\begin{array}{c}\text { Average } \\
\text { Silhouette }\end{array}$ & 0.371 & $\mathbf{0 . 4 8 1}$ & 0.469 & $\mathbf{0 . 4 7 1}$ & 0.282 \\
\hline
\end{tabular}

*Bold figures indicate Xie - Beni indices and average silhouette statistics possibly associated with optimal number of clusters.

Table 4: Membership Degree Matrix of East Asian Economies (1990 - 2000)

\begin{tabular}{|c|c|c|c|c|}
\hline Economy & Cluster 1 & Cluster 2 & Cluster 3 & Cluster 4 \\
\hline China & 0.0533 & 0.0606 & $\mathbf{0 . 8 6 8 7}$ & 0.0173 \\
\hline Hong Kong & $\mathbf{0 . 6 4 4 3}$ & 0.1413 & 0.1631 & 0.0514 \\
\hline Indonesia & 0.0002 & 0.0002 & 0.0002 & $\mathbf{0 . 9 9 9 5}$ \\
\hline Japan & 0.1636 & $\mathbf{0 . 6 0 7 3}$ & 0.1842 & 0.045 \\
\hline Korea & 0.1358 & $\mathbf{0 . 7 3 2 2}$ & 0.0964 & 0.0356 \\
\hline Malaysia & $\mathbf{0 . 9 2 6 4}$ & 0.0459 & 0.02 & 0.0078 \\
\hline Philippines & 0.0464 & 0.0835 & $\mathbf{0 . 8 5 2 2}$ & 0.0179 \\
\hline Singapore & $\mathbf{0 . 6 0 6 5}$ & 0.2629 & 0.1049 & 0.0256 \\
\hline Taiwan & 0.1112 & $\mathbf{0 . 7 9 3 9}$ & 0.0817 & 0.0132 \\
\hline Thailand & $\mathbf{0 . 3 8 9 6}$ & 0.376 & 0.1501 & 0.0844 \\
\hline
\end{tabular}

*Bold figures indicate the associated cluster

The first group consists of Hong Kong, Singapore, Malaysia and Thailand. The financial crisis had driven Hong Kong's business cycle and its rate of inflation close to the regional ones and thus brings the territory to the same group with major Southeast Asian economies. This group features high degree of openness to trade, highly synchronized business cycles with the regional 


\section{International Journal of Social Science and Economic Research}

ISSN: $2455-8834$

Volume: 05, Issue: 03 "March 2020"

cycle and fairly low rates of inflation. The fact that the hard-hit Korea experienced rapid exchange rate depreciation and lower inflation following the crisis make it no longer in the same group with the Southeast Asian nations. The manufacturing-intensive economies of Japan, Korea and Taiwan preferably constitute the second group of which the main characteristics are low inflation rates, low degree of openness to regional trade and higher exchange rate volatility. China and the Philippines form the third group since they both had high inflation rates, average degree of export diversification and low degree of business cycle synchronization. The worst victim of the East Asian financial crisis is probably Indonesia. The economy suffered from the extremely deep depreciation of the Rupiah and from very high inflation. Indonesia was also very open to regional trade and had highly diversified export structure as well. It is no surprise that the economy constitutes its own group.

For the period of 2001-2018, we find that the first group includes China and Thailand. The fact that China is the second largest trade partner of Thailand in 2019 suggests that trade might be the key driver of synchronization between the economies. The second group contains of Singapore and Taiwan province of China. We do not find any reasonable explanation of this homogeneity between the economies. We see in the third group Malaysia, the Philippines and Hong Kong. Korea and Japan join the same groups, probably since they have similar economic structures and level of development. Indonesia constitutes its own group with no other economies.

Table 5: Membership Degree Matrix of East Asian Economies (2001 - 2018)

\begin{tabular}{|c|c|c|c|c|c|}
\hline Economy & Cluster 1 & Cluster 2 & Cluster 3 & Cluster 4 & Cluster 5 \\
\hline China & $\mathbf{0 . 9 3 7}$ & 0.016 & 0.018 & 0.011 & 0.019 \\
\hline Hong Kong & 0.121 & 0.219 & $\mathbf{0 . 4 5 0}$ & 0.128 & 0.081 \\
\hline Indonesia & 0.001 & 0.001 & 0.002 & $\mathbf{0 . 9 9 4}$ & 0.001 \\
\hline Japan & 0.281 & 0.101 & 0.144 & 0.077 & $\mathbf{0 . 3 9 7}$ \\
\hline Korea & 0.013 & 0.007 & 0.009 & 0.009 & $\mathbf{0 . 9 6 1}$ \\
\hline Malaysia & 0.022 & 0.019 & $\mathbf{0 . 9 3 5}$ & 0.013 & 0.011 \\
\hline Philippines & 0.092 & 0.073 & $\mathbf{0 . 6 2 0}$ & 0.127 & 0.088 \\
\hline Singapore & 0.048 & $\mathbf{0 . 8 5 6}$ & 0.042 & 0.028 & 0.026 \\
\hline Taiwan & 0.077 & $\mathbf{0 . 7 4 3}$ & 0.094 & 0.036 & 0.049 \\
\hline Thailand & $\mathbf{0 . 4 1 8}$ & 0.270 & 0.147 & 0.087 & 0.077 \\
\hline
\end{tabular}

*Bold figures indicate the associated cluster

The comparison between two periods reveal some interesting findings. First, it seems that the regional economies are diverging in term of OCA criteria, as the number of groups increases from four to five. Second, there are changes in the grouping of economies. While Japan and Korea still stay in the same group, Indonesia still stands alone, others have changed their 
International Journal of Social Science and Economic Research

ISSN: $2455-8834$

Volume: 05, Issue: 03 "March 2020"

grouping partners. All in all, it seems that East Asia economies have been fairly dispersed in terms of the OCA criteria. We find no clear trend of convergence through our fuzzy clustering analysis. Instead, the region has appeared even more diverged after the 1997 - 1998 financial crisis. The divergence can be seen clearly in the ASEAN economies. Indonesia, in particular, has moved far apart other neighbors due to much higher inflation rate, highly volatile exchange rate and low degree of synchronization. Philippines have moved towards its neighbors. Thailand stays somewhere in between its ASEAN neighbors and the Northeast economies. Similarly, Taiwan's position is indeterminate between grouping with China and grouping with Japan. In all periods, we witness the presence of high degree of fuzziness.

\section{CONCLUSION}

This paper seeks the empirical evidence on the readiness of East Asian economies for a currency union using data of two periods from 1990 to 2000 and 2001 to 2018. Applying the method of fuzzy C-mean clustering analysis, we attempt to examine the degree of homogeneity across the economies in terms of multiple OCA criteria by classifying them into groups within which they are at most similar. We find that East Asia has been fairly dispersed and can be divided into about four or five groups with significant degree of fuzziness. We find no notable trend of convergence from the data. In fact, East Asian has appeared to be more diverged despite growing integration and intra-regional trade. This reflects the diversity of the region in term of economic development and macroeconomic policies. Thus, we suspect the possibility of forming a currency union in East Asia in any near future.

\section{REFERENCES}

[1] H. K. Chow and Y. Kim, "A common currency peg in East Asia? Perspectives from Western Europe," Journal of Macroeconomics, vol. 25, no. 3, pp. 331-350, Sep. 2003, doi: 10/fh9bjc.

[2] G. S. Tavlas, "The 'New' Theory of Optimum Currency Areas," The World Economy, vol. 16, no. 6, pp. 663-685, 1993, doi: 10/cm39db.

[3] P. Masson and M. Taylor, Eds., Policy Issues in the Operation of Currency Unions. Cambridge University Press, 1993.

[4] P. R. Masson and M. P. Taylor, "Optimal Currency Areas: A Fresh Look at the Traditional Criteria," in Varieties of Monetary Reforms: Lessons and Experiences on the Road to Monetary Union, P. L. Siklos, Ed. Boston, MA: Springer US, 1994, pp. 23-43. 
International Journal of Social Science and Economic Research

ISSN: 2455-8834

Volume: 05, Issue: 03 "March 2020"

[5] T. Bayoumi and B. Eichengreen, "One Money or Many? Analysing the Prospects for Monetary Unification in Various Parts of the World," International Economics Section, Departement of Economics Princeton University, 1994.

[6] O. J. Blanchard and D. Quah, "The Dynamic Effects of Aggregate Demand and Supply Disturbances," The American Economic Review, vol. 79, no. 4, pp. 655-673, 1989.

[7] A. W. Gregory, A. C. Head, and J. Raynauld, "Measuring World Business Cycles," International Economic Review, vol. 38, no. 3, pp. 677-701, 1997, doi: 10/b26kf4.

[8] M. A. Kose, C. Otrok, and C. H. Whiteman, "International Business Cycles: World, Region, and Country-Specific Factors," American Economic Review, vol. 93, no. 4, pp. 1216-1239, Sep. 2003, doi: 10/dqsgsz.

[9] Robert J. Hodrick and Edward Prescott, "Post-War U.S. Business Cycles: An Empirical Investigation," Northwestern University, Center for Mathematical Studies in Economics and Management Science, 1981.

[10] P. B. Kenen, "The theory of optimum currency areas : an eclectic view," Monetary problems of the international economy, 1969.

[11] J. C. Bezdek, "Fuzzy mathematics in pattern classification," 1973.

[12] V. J. Rayward-Smith, F. Hoeppner, F. Klawonn, R. Kruse, and T. A. Runkler, "Fuzzy Cluster Analysis: Methods for Classification, Data Analysis and Image Recognition," 1999.

[13] X. L. Xie and G. Beni, "A validity measure for fuzzy clustering," IEEE Transactions on Pattern Analysis and Machine Intelligence, vol. 13, no. 8, pp. 841-847, Aug. 1991, doi: 10/b38x3h. 